Liberal Education", and contributed to Dunbar and Barker's "Greek and English Lexicon" (1831), Lemprière's "Classical Dictionary" (1838), and Green. hill's "Theophilus" (1842). Adams was not only a great scholar but was also an excellent doctor. "His first love and his last", says Prof. Singer, was his practice, his patients and the poor." His devotion to his profession was best shown by his declining the chair of Greek at the University of Aberdeen, which afterwards gave him an honorary doctorate. He paid several visits to Oxford and London, where he made friends with many learned men, particularly James Quain and William Sharpey, the founders of the modern academic teaching of anatomy and physiology in England. Dr. Singer ends his fine essay by saying that though the ranks of general practitioners in Britain have produced many eminent men of science, such as J. A. Lockhart, Sir James Mackenzie and J. A. MacMunn, none of equal distinction as a scholar practised in so isolated a locality as Adams.

\section{A Pilot-Channel Regulator for the K-I Carrier System}

VARIATIONS in attenuation of the cable conductors used for the K-l carrier system are compensated by corresponding changes of gain under control of a pilot-wire regulating system. Since these changes in attenuation are due primarily to temperature changes, and since all pairs in the same cable are approximately at the same temperature, a pilot regulation systemin which the gain over the various pairs is adjusted to conform to the temperature of one pair of wires in the cable-is a simple and satisfactory way of handling the regulation. There are, however, certain minor deviations from pair to pair for which such a system will not provide, and with long circuits over, say, some five hundred miles, some additional regula. tion will be needed to take care of these residual deviations.

An article by J. H. Bollman (Bell Lab. Rec., 20, No. 10 ; June, 1942) describes a regulator using thermistors as controlling elements, supplementing the normal regulating system. The new regulator operates on pilot channels rather than on a pilotwire. Currents of single-frequeney are transmitted over a pair of conductors, the gain being regulated in accordance with the attenuation changes of these pilot channels. Regulation is thus directly associated with the carrier system operating on that pair. The change in gain is the same at all frequencies. Regula. tion as designed is used not only to compensate for the residual regulation errors of a 300-500 mile circuit, but also to take care of the flat regulation of the previous repeater section (12-20 miles) and also the slope and bulge regulation of the previous twist section (50-300 miles), obviating the necessity for pilot-wire and twist regulators. Measurements over a four-monthly period, using continuous recorders, showed that variations in the net losses of the twelve channels due to changes in line loss were not more than $0.5 \mathrm{db}$, an improvement of more than two to one as compared to the performance previously available without the deviation regulator.

\section{Overheating of Electric Motors}

AN article on this subject in the Electrical Review of July 31 opens with a brief survey of overheating due to dirt or other foreign matter obstructing the ventilating pipes, ducts and passages of motors. Mention is made of the lagging effect which waste materials may have on the motor casing, and useful suggestions are given for the improvement and maintenance of ventilation. Since the rate of heat generation is proportional to the square of the load, protection against overloading is advised. It is suggested that motors be protected by a tripping device operating at 25 per cent sustained overload, or thermostatically controlled if subjected to large rapid load fluctuations. The liability of cotton insulation to char at about $100^{\circ} \mathrm{C}$. is mentioned in stressing the safe temperature rise of $a$ winding as being about $72^{\circ} \mathrm{C}$. above that of the surrounding atmosphere.

The author then outlines the effects of accidentally sustained starting currents, mentioning in this connexion the mal-operation of star-delta starters. Warnings are given against running D.c. variablespeed motors at abnormal speeds; series connecting the windings of small A.c. motors intended for use on two voltages when on full load; prolonged connexions of the starting windings of split-phase singlephase motors; and the running of polyphase motors with one phase of the supply open-circuited. The remainder of the article is devoted to interesting points in maintenance, attention being directed to worn bearings, lubrication, short-circuited windings, short-circuiting of commutators by carbon dust, and the careless handling of dismantled machines as possible causes of overheating. Attention to the many points referred to will doubtless minimize the risk of overheating, rapid deterioration and breakdown of the plant.

\section{Rats and the War}

According to the Medical Officer of August 15, Dr. Charles White, medical officer of health for the City of London, has recently issued a report to the effect that while the devastation caused by enemy action has undoubtedly reduced the rat population, particularly in the Cripplegate area, in other districts there is still severe infestation by these vermin. Premises previously more or less free now suffer constant infestation, especially buildings in which the upper floors only were damaged by fire or blast. The hundreds of sandbag blast walls have formed a safe harbour for rats, but many have now been replaced by brick structures. Infestation by rats has been aggravated by the introduction of fire-guarding and consequent indiscriminate feeding, as well as by leaving doors open throughout the buildings to facilitate fire-guards access to rooms. Dr. White recommends that when structural reconstruction is considered adequate steps should be taken to construct rat-free buildings.

\section{The National Trust}

IT is satisfactory to learn from the forty-seventh annual report of the National Trust for Places of Historic Interest or Natural Beauty that progress is being made in spite of the War. The recent outstanding addition to the Trust's properties is the Wallington estate in Northumberland, but while this is the largest (13,000 acres) there are many other interesting and beautiful places now saved for the nation in no less than twelve counties. The report, which is also concerned with problems of future upkeep, preservations of buildings and amenities, and of the plant, fish and even bird life of Ullswater, can be obtained at 7 Buckingham Palace Gardens, Westminster, and is a cheering document to turn to in this time of strife and destruction. 